\title{
Meat avoidance and body weight concerns: nutritional implications for teenage girls
}

\author{
BY YVONNE M. RYAN
}

Department of Biological Sciences, Dublin Institute of Technology, Kevin Street and Unit of Nutrition and Dietetics, Department of Clinical Medicine, Trinity College Medical School, St James's Hospital, Dublin 8, Republic of Ireland

In a report on vegetarianism recently published by the British Nutrition Foundation (1995) it was noted that, between 1988 and 1994 there was a threefold rise in the proportion of women, aged between 16 and 64 years who avoided eating meat. This dramatic increase in the popularity of meat avoidance has raised many concerns about the adequacy of a meatless diet, in particular for teenage girls because of their high nutritional requirements. The present paper briefly addresses the reasons why teenage girls choose to avoid eating meat and investigates the effects of meat avoidance on Fe status during the teenage years.

\section{REASONS FOR AVOIDING MEAT}

There are many reasons why vegetarians decide to avoid eating meat. Most, however, both young and old, say that an abhorrence of cruelty to animals is their main reason and often, a dislike of the taste of meat and perceived health benefits are other common reasons given (Reddy \& Sanders, 1990).

Recently a questionnaire survey was carried out on 420 15-year-old Dublin schoolgirls and $34 \%(n 141)$ reported that they avoid or would like to avoid eating meat and their reasons are shown in Table 1 . 'Eating meat is cruel to animals' was the most popular reason given by the girls $(53 \%)$ followed by a dislike of the taste of meat $(51 \%)$. Over onequarter of the girls $(29 \%)$ reported that they avoid or would like to avoid eating meat because 'meat is a fattening food'. This finding supports recent evidence which suggests that the increased popularity of meat avoidance by teenage girls may be linked with a desire to reduce body weight (Sanders \& Reddy, 1994).

\section{Meat avoidance and slimming among teenage girls}

To investigate this hypothesis further the weight concerns of these Dublin schoolgirls ( $n$ 420) were assessed and, in agreement with the findings of Hill et al. (1992) in British teenagers, a high level of dissatisfaction with body weight was found in this study. Of the teenage girls surveyed, $60 \%$ ( $n$ 247) reported that they were 'not happy with their weight' and 'wanted to be lighter' and $68 \%(n 286)$ had 'tried to lose weight in the past'. Furthermore, over three-quarters $(n 323)$ of the subjects agreed that 'meat is a fattening food', supporting Thomas's (1990) suggestion that healthy-eating guidelines which encourage a decreased saturated fat intake by reducing consumption of meat and meat products may be misinterpreted by teenage girls leading to the concept that meat is 'fattening'. A comparison of the weight concerns of 'meat eaters' ( $n$ 279) with 'reduced meat eaters' (subjects ( $n$ 141) who reported that they avoid or would like to avoid eating meat) showed that the proportion of girls who 'wanted to be slimmer' was higher among 
Table 1. Reasons for avoiding meat from a survey of 15-year-old Dublin schoolgirls who avoid or would like to avoid meat (n 141)

\begin{tabular}{ll}
\hline \multicolumn{1}{c}{ Reason } & $\%^{*}$ \\
\hline Eating meat is cruel to animals & 53 \\
I do not like the taste of meat & 51 \\
Meat is a fattening food & 29 \\
Vegetarian diets are more healthy & 23 \\
\hline
\end{tabular}

*46\% (n 65) of the girls gave more than one reason and, therefore, the total percentage does not equal 100 .

the 'reduced meat eaters' compared with the 'meat eaters' (75 v. 61\%, $P=0.003$ ) and more of the 'reduced meat eaters' had 'tried to lose weight' (80v.62\%,P=0.002).

Similarly, Nelson et al. (1993) showed a higher prevalence of Fe-deficiency anaemia associated with lower dietary Fe intakes in British schoolgirls ( $n$ 197, aged $12-14$ years) who had tried to lose weight compared with those who had not $(23 v .7 \%, P=0.002)$.

Therefore, considerations of body weight and the general misperception that 'meat is a fattening food' appear to be important influences on meat consumption patterns among teenage girls.

\section{EFFECTS OF MEAT AVOIDANCE ON IRON STATUS DURING ADOLESCENCE}

Many factors contribute to a marked rise in the requirement for dietary Fe during the teenage years. The following section briefly describes these factors and examines how males and females differ in their need for Fe during this time.

\section{Iron requirements in males}

In males, requirements for $\mathrm{Fe}$ include that needed to replace basal losses and to meet the demands of growth (see Fig. 1). Basal losses comprise Fe that is lost with cells shed from the interior and exterior surfaces of the body including skin, intestines, urinary tract and airways. This loss is largely influenced by body size and is estimated to be about $14 \mu \mathrm{g} / \mathrm{kg}$ body weight per d (Hallberg \& Rossander-Hulthén, 1991).

In relation to growth requirements, the adolescent growth spurt in boys occurs between the ages of 13 and 14 years, with sexual maturation typically starting 2 years before peak growth and lasting for about 3 years. This sequence of events, however, can take place either much earlier or later and is associated with a sharp increase in the need for absorbed Fe from about 1.0 to $2.5 \mathrm{mg} / \mathrm{d}$. After this period of high Fe requirements, there is a rapid decrease in the rate of growth and consequently in the need for Fe, providing, therefore, an opportunity to recover from the Fe depletion that might have developed during peak growth (Dallman, 1992).

\section{Iron requirements in females}

Due to the onset of menstruation, the adolescent increase in Fe requirement is distributed over a much longer period in females than in males (see Fig. 2). Peak growth in girls occurs earlier than in boys at a mean of 11.5 years; sexual maturation begins 1 year before this and continues for a total of 4 years, with menarche typically starting about 1 year after peak growth. The mean requirement for absorbed Fe reaches a maximum of about $1.5 \mathrm{mg} / \mathrm{d}$ at 


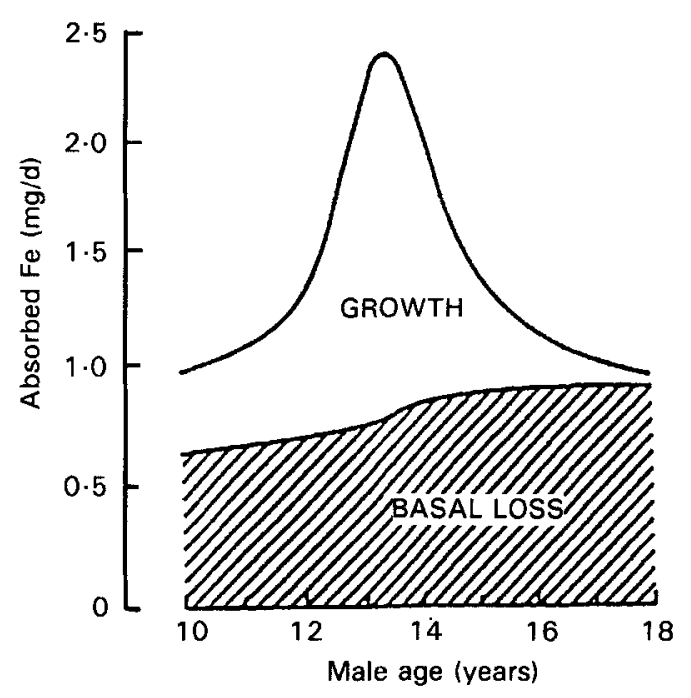

Fig. 1. Iron requirements in males. (From Dallman, 1992; reproduced with the permission of Nestec Ltd.)

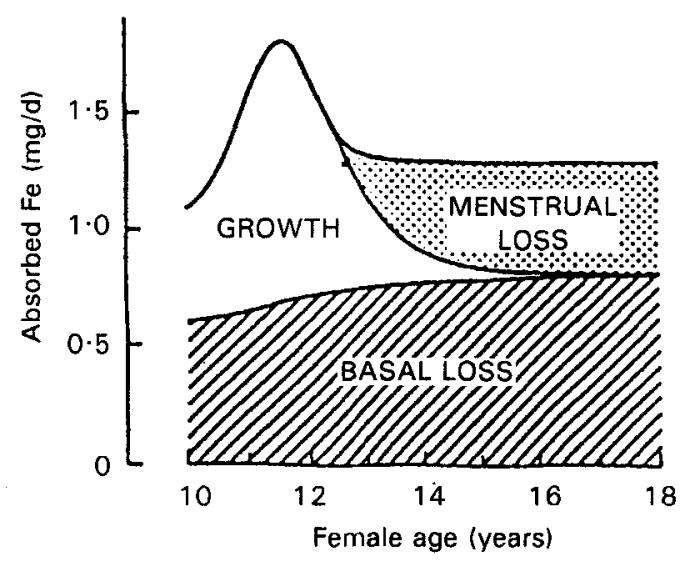

Fig. 2. Iron requirements in females. (From Dallman, 1992; reproduced with the permission of Nestec Ltd.)

peak growth, but does not return to its earlier baseline. Instead, it settles at a higher level of about $1.3 \mathrm{mg} / \mathrm{d}$ due to the new requirement to replace menstrual Fe losses (Dallman, 1992).

Fe status in females has been shown to be determined largely by Fe losses during menstruation. In a study examining factors associated with Fe depletion in a group of 446 women, aged between 17 and 50 years, Fogelholm et al. (1993) reported that Fe stores were negatively affected by both high frequency of menstruation (high $v$. low frequency groups had serum ferritin levels of $23.3 v .42 .5 \mu \mathrm{g} / \mathrm{l}$ respectively; $P<0.05$ ) and prolonged menstrual bleeding time ( $>6 \mathrm{~d} v .4-5 \mathrm{~d}$ corresponded with serum ferritin levels of $22.6 v$. $29.4 \mu \mathrm{g} / \mathrm{l}$ respectively; $P<0.05)$.

Although menstrual blood losses in individual women tend to be constant throughout fertile life there is a marked variation in losses between different women (Hallberg \& Rossander-Hulthén, 1991). In a study on 476 Swedish women, Hallberg et al. (1966) 
reported that the median monthly blood loss was $30 \mathrm{ml}$ corresponding to a daily Fe loss of $0.5 \mathrm{mg}$. Women at the 95th centile, however, had losses of up to $118 \mathrm{ml}$ blood per menstrual period, equivalent to $1.9 \mathrm{mg} \mathrm{Fe}$.

Therefore, for Fe balance to be maintained in teenage girls the amount of Fe absorbed daily from the diet must be sufficient to meet the demands of growth and to compensate for daily Fe losses, both basal and especially menstrual losses (MacPhail \& Bothwell, 1992).

\section{The regulation of iron balance}

Hallberg et al. (1995) reported that the body has several systems or adaptive mechanisms which strive to protect Fe status even despite very high physiological requirements for Fe. It is well established that dietary Fe absorption has a key role to play in the maintenance of Fe balance (Hallberg et al. 1995). New research, however, indicates that the amount of Fe in stores may be the main factor that controls the quantity of $\mathrm{Fe}$ absorbed from the diet. Evidence of this was presented by Hulthén et al. (1995) who showed a significant negative correlation $(P<0.001)$ between serum ferritin and Fe absorption (see Fig. 3).

More recently, Antilla \& Simes (1996) in an 18-month follow-up study of sixty 11and 12-year-old males, showed that, as the boys progressed through puberty their serum ferritin concentrations fell. The authors suggest that this does not necessarily indicate $\mathrm{Fe}$ depletion but reflects $\mathrm{Fe}$ moving from stores for erythropoiesis and that decreasing stores leads to increased Fe absorption supplying most of the Fe needs of the boys.

Furthermore, studies have shown that, although the incidence of Fe-deficiency anaemia in vegetarians is not significantly different from that of 'meat eaters', their Fe stores are frequently reduced (Helman \& Darton-Hill, 1987; Reddy \& Sanders, 1990; Alexander et

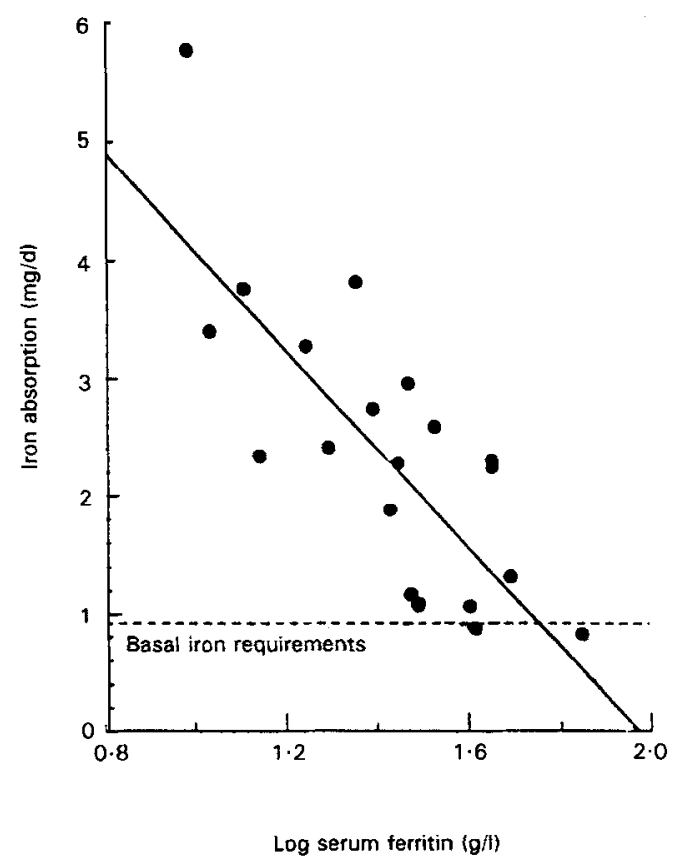

Fig. 3. Relationship between iron stores and iron absorption. (From Hulthén et al. 1995; reproduced with the permission of Macmillan Press Ltd.) 
Table 2. Factors that influence dietary iron absorption (From Craig, 1994)

\begin{tabular}{ll}
\hline \multicolumn{1}{c}{ Enhancers } & \multicolumn{1}{c}{ Inhibitors } \\
\hline Ascorbic acid & Phytates (bran) \\
Meat, fish and poultry & Polyphenols (tannins) \\
Citric, malic and other organic acids & Zn and other divalent cations \\
Fermented foods & Soyabean proteins \\
& $\mathrm{Ca}$ \\
\hline
\end{tabular}

al. 1994). It is possible that this may be an adaptive response in vegetarians, similar to that described in adolescent boys and facilitates maximum absorption of the less-available nonhaem-Fe, assisting in the regulation of Fe balance.

In addition, results from surveys which have examined the Fe status of menstruating women have found that between 16 and $30 \%$ have low Fe stores; however, the prevalence of Fe deficiency anaemia is much lower, ranging between 2 and $5 \%$ (Hallberg, 1995). A finger-prick blood sample was used to assess the Fe status of a subgroup of 201 Dublin schoolgirls who participated in the questionnaire survey. Low Fe stores (serum ferritin $\leq 15 \mu \mathrm{g} / \mathrm{l}$ ) were identified in $42 \%$ of the girls, only $3 \%$, however, were found to be Fe deficient (haemoglobin $<120 \mathrm{~g} / \mathrm{l}$ ). Although the higher the prevalence of low Fe stores in a population the greater the risk of Fe deficiency anaemia, in the majority of cases, low $\mathrm{Fe}$ stores do not appear to predict the development of Fe-deficiency anaemia.

In summary, these findings seem to suggest that low Fe stores may not be a cause for concern; declining serum ferritin concentrations may reflect a 'normal' physiological response that has a part to play in maintaining Fe homeostasis. There is, however, a limit to this adaptive process and Hallberg et al. (1995) have recently defined what they described as a 'a critical point' at which insufficient amounts of dietary Fe are absorbed to balance $\mathrm{Fe}$ losses. At this point, the serum ferritin concentration falls to below $15 \mu \mathrm{g} / \mathrm{l}$, Fe begins to disappear in bone-marrow smears and the haemoglobin concentration starts to decrease. The point at which this limit is reached is determined largely by the characteristics of the diet consumed or, more specifically, by its haem and non-haem-Fe content and by the balance between factors present in the diet that enhance or inhibit Fe absorption. These factors are summarized in Table 2.

In vegetarians, although non-haem-Fe is much less absorbable than haem-Fe (2-20\% $v .15-35 \%$; Craig, 1994), the presence of enhancing factors, when consumed at the same meal will greatly increase, perhaps by fourfold the amount of non-haem-Fe absorbed (Monsen, 1988).

\section{CONCLUSIONS}

Although requirements for $\mathrm{Fe}$ are high in teenage girls, an appropriately-planned and varied vegetarian diet is compatible with an adequate $\mathrm{Fe}$ status. Knowledge of dietary factors that enhance non-haem-Fe absorption is important to enable young meat avoiders to make sensible, healthy food choices (Craig, 1994). However, the link between meat avoidance and a 'desire to be thinner' suggests that some teenagers may choose to avoid meat and other foods also perceived as fattening solely to lose weight, and, in contrast to those committed to a lifetime of meat avoidance for moral or health reasons, may fail to adequately compensate for the lack of haem-Fe and other nutrients in their 'meatless' diet, greatly increasing the risk of nutrient deficiencies. 


\section{REFERENCES}

Alexander, D., Ball, M. J. \& Mann, J. (1994). Nutrient intake and haematological status of vegetarians and agesex matched omnivores. European Journal of Clinical Nutrition 48, 538-546.

Antilla, R. \& Simes, M. A. (1996). Senum transferrin and ferritin in pubertal boys: relations to body growth, pubertal stage, erythropoiesis, and iron deficiency. American Journal of Clinical Nutrition 63, 179-183.

British Nutrition Foundation (1995). Vegetarianism. The Report of the BNF Task Force. London: British Nutrition Foundation.

Craig, W. J. (1994). Iron status of vegetarians. American Journal of Clinical Nutrition 59, 1233S-1237S.

Dallman, P. R. (1992). Changing iron needs from birth through adolescence. In Nutritional Anaemias. Nestlé Nutrition Workshop Series, pp. 29-38 [S. J. Fomon and S. Zlotkin, editors]. New York: Vevey/Raven Press Ltd.

Fogelholm, M., Alopaeus, K., Silvennoinen, T. \& Teirila, J. (1993). Factors affecting iron status in non-pregnant women from urban South Finland. European Journal of Clinical Nutrition 47, 567-574.

Hallberg, L. (1995). Results of surveys to assess iron status in Europe. Nutrition Reviews 53, 314-322.

Hallberg, L., Hogdahl, A.-M., Nillson, L. \& Rybo, G. (1966). Menstrual blood loss: a population study. Variation at different ages and attempts to define normality. Acta Obstetrica et Gynecologica Scandinavica $45,320-351$.

Hallberg, L., Hulthén, L., Bengtsson, C., Lapidus, L. \& Lindstedt, G. (1995). Iron balance in menstruating women. European Journal of Clinical Nutrition 49, 200-207.

Hallberg, L. \& Rossander-Hulthén, L. (1991). Iron requirements in menstruating women. American Journal of Clinical Nutrition 54, 1047-1058.

Helman, A. D. \& Darton-Hill, I. (1987). Vitamin and iron status in new vegetarians. American Journal of Clinical Nutrition 45, 785-789.

Hill, A. J., Oliver, S. \& Rogers, P. J. (1992). Eating in the adult world: The rise of dieting in childhood and adolescence. British Journal of Clinical Psychology 31, 95-105.

Hulthén, L., Gramatkovski, E., Gleerup, A. \& Hallberg, L. (1995). Iron absorption from the whole diet. Relation to meal composition, iron requirements and iron stores. European Journal of Clinical Nutrition 49, 794-808.

MacPhail, P. \& Bothwell, T. H. (1992). The prevalence and causes of nutritional iron deficiency anemia. In Nutritional Anaemias, Nestle Nutrition Workshop Series, vol. 30, pp. 1-12 [S. J. Fomon and S. Slotkin, editors]. New York: Vevey/Raven Press Ltd.

Monsen, E. R. (1988). Iron nutrition and absorption: dietary factors which impact iron bioavailability. Journal of the American Dietetic Association 88, 786-790.

Nelson, M., White, J. \& Rhodes, C. (1993). Haemoglobin, ferritin, and iron intakes in British children aged 1214 years: a preliminary investigation. British Journal of Nutrition 70, 147-155.

Reddy, S. \& Sanders, T. A. B. (1990). Haematological studies on pre-menopausal Indian and Caucasian vegetarians compared with Caucasian omnivores. British Journal of Nutrition 64, 331-338.

Sanders, T. A. B. \& Reddy, S. (1994). Vegetarian diets and children. American Journal of Clinical Nutrition 59, $1176 S-1181 S$.

Thomas, B. (1990). Meat, Diet and Health. London: The Meat and Livestock Commission. 